\title{
EL CIUDADANO: PARADIGMA DE LA ESCUELA ARGENTINA
}

\author{
Antonia Delia Muscia*
}

RESUMEN - el ciudadano se convirtió en modelo de "buen hombre" a principios de siglo. Los manuales escolares susten-taron una ética naturalista, inmanente y civica.

PALABRAS CLAVES - textos escolares, ciudadano, política educativa.
ABSTRACT - The citizen became the model of the "morally good man" from the beginning of the century, in the school books. That ethics was naturalistic, immanent and civic.

KEY WORDS - school books, citizen, educational politics.

Desde un enfoque interdisciplinario, iniciamos en 1994, el Proyecto Contenido ideológico de textos escolares argentinos. Nivel primario. Tomamos como objeto y fuente de nuestra investigación histórico-educativa los manuales escolares y al abordarlos desde una perspectiva ideológica, puntualizábamos que

“ideología se emplea en una doble acepción, hoy comúnmente admitida: de un lado, como concepción del mundo propia de un determinado grupo histórico concreto; del otro, como deformación de la realidad, como falsa representación que emana de un grupo social; enmascara una situación de interés ligada a una estructura social determinada"."

Desde esos dos supuestos fundamentales intentamos descubrir el proceso de apropiación de los saberes en la escuela a partir de los manuales escolares: los presupuestos filosóficos de sus autores y la política educativa ${ }^{2}$ Se han formado varias áreas para el estudio de textos: Moral e Instrucción Cívica; Historia Nacional; Educación Especial en Mendoza; Ciencias Biológicas; Libros de Lectura (métodos de enseñanza de la lectura y evolución del curriculum; lo ideológico y lo literario); Lenguas Extranjeras (francés). ${ }^{3}$

* Profesora de Filosofía, titular de la cátedra de Historia de la Educación I, Carrera de Ciencias de la Educación, Facultad de Filosofia y Letras de la Universidad Nacional de Cuyo. Mendoza, Argentina. Investigadora Asociada al Proyecto MANES (Manuales Escolares de España e Tberoamérica. 1812-1990). U.N.E.D. Madrid. Directora del proyecto presentado.

1 PUELLEZ BENITEZ, M. Educación e ideología en España contemporánea. 2. ed. Barcelona: Labor, 1986, p. 9.

2 Ver CHOPIN, A. Les manuels scolaires. Histoire et actualité. Paris, Hachette. 1992. "Celui qui est maitre su libre est maittre de l'éducation" (p. 22).

3 A cargo de especialistas de nuestra Facultad. Becados por la Secretaría de Políticas Universitarias y con un subsidio anual de la Secretaria de Ciencias y Técnica de la Universidad Nacional de Cuyo y dos becarios de ésta. 


\section{1 - La educación y el proyecto político}

Partimos de la suposición de que los manuales escolares refiejan y promueven los objetos del proyecto político de la clase dirigente, cuyo espíitu se expresa a través de la legislación escolar. Nos propusimos mostrar la función a la escuela como canal de difusión de esa ideología a través de manuales, planes de estudio y programas, aunque destacando la acción retardada en la producción en los manuales que la reflejan. Nos preguntábamos en qué tiempo y medida esos textos reflejaban las nuevas visiones científicas, pedagógicas y metodológicas.

Sobre tres siglos de cultura española, la educación argentina ha tenido como constante su base cristiana, según el magisterio de la Iglesia Católica. Sus principios convivieron con las sucesivas novedades filosóficas, políticas y pedagógicas europeas y estadouniđiense del s. XVIII y XIX. La preocupación por la instrucción pública, la fe en el progreso gracias a ella, la necesidad de actualizar los contenidos de la enseñanza y la tendencia del Estado a expandir y solventar la educación "aparecen tempranamente en el país; para ser más precisos: aparecen con el pais". 4

En la segunda mitad del s. XIX, el problema dominante en la reflexión filosófica de los argentinos fue el hombre. El tema fue analizado desde un doble enfoque: el espiritualismo y el materialismo. Una división muy amplia, pero que indica la aparición del positivismo, en el sector de la generación de 1880, que dio base jurídica a la escuela pública nacional. Sin embargo, en la formación recibida por los maestros normales, en gestión por aquellos años, fue el del eclecticismo espiritualista el que matizó el fondo romántico-historicista y la presencia continua del ideario iluminista, de sesgo empirista y utilitarista. Pestalozzi, ${ }^{5}$ Froebel y Herbart se combinaron con el krausismo y rivalizaron con $\mathrm{H}$. Spencer.

La escuela pública se organiza a partir de 1884, con la Ley de Educación Común, cuyo espíritu estaba inspirado en el espíritu francés, laico y liberal. La universalidad, obligatoriedad, gratuidad, gradualidad y laicidad de la ley y sus correspondientes reglamentaciones asi lo atestiguan. Las autoridades educativas se concentraron en solucionar dos grandes problemas: el alto nivel de analfabetismo y la integración cultural de la masa de inmigrantes que se incorporaba al pais.

Durante el s. XIX la idea eje que inspiró a la educación fue la de idea de progreso. Sus objetivos fueron: la reforma radical de las costumbres, la modernización del país, la aceleración del progreso socio-económico y la homogeneización cultural y civica de la población. ${ }^{6}$

4 MUSCTA, A. El proceso de secularización de la educación en Argentina. La generación de 1880. En "Jornadas de Ciencias Económicas 1994". Tomo de Disciplinas Humanisticas.(P. 665-685) Mendoza, Facultad de Ciencias Económicas (UNC), 1994, p. 665.

5 Ver URZI, S. "Las corrientes pedagógicas que influyeron en la enseñanza de la lectura". En: Revista Educación Cuyo, Mendoza, Facultad de Filosofia y Letras (UNC), n. 6, 1998. Forma parte de nuestro proyecto.

6 Véase: ZANOTTI, L. J. En el centenario de la Ley 1.420. Buenos Aires: E. América Latina, 1985. En: Revista del Instituto de Investigaciones Educativas, Buenos Aires, E. América Latina, n. 46, 1984. 
En la última década del ochocientos aparece "un decisivo tono chauvinista" 7 acentuado a partir de 1908. Los planes de estudio y programas para la escuela primaria de 1910 se denominan "educación nacionalista". ${ }^{8}$ La exacerbación del sentimiento patriótico, iniciado hacia 1891, se proponía ahora a formar sentimiento y conciencia cívica y política: difundir los derechos del ciudadano y fomentar su participación política por medio del sufragio.

"El Estado, con fuerte voluntad política y consciente de su poder, implanta el paradigma del buen ciudadano en la escuela como medio de lograr la integración de todos los miembros de la sociedad. ${ }^{9}$ Crear la conciencia de una 'común pertenencia', un ideario que imprimiese el 'carácter nacional' e identificase a cada ciudadano como parte de un todo: la nación. ${ }^{10}$ Así la formación y afirmación de la ciudadanía contribuyó a producir y preservar la memorial social." 11

\section{2 - Manuales escolares de Moral e Instrucción Cívica ${ }^{12}$}

Elegimos los manuales oficialmente aprobados, según las pautas de los Reglamentos para concursos de textos, del Consejo Nacional de Educación. Su gestión centralizada nos permitió acceder a ellos a través de El Monitor de la Educación Común, publicación oficial del CNE. ${ }^{13}$

Dada la lectura ya establecida de la Historia de las Ideas Filosóficas en nuestro país, buscábamos en la enseñanza de la Moral, la presencia del positivismo a partir de una guía de análisis (cualitativo y cuantitativo) cuyos ejes intentaban ver las concepciones: de la Historia, de lo ético-antropológico, de lo económico y social y del positivismo científico y pedagógico. ${ }^{14} \mathrm{El}$ resultado de esa búsqueda fue una gran sorpresa: no hubo entre 1884 y 1910 una Moral con fundamentos positivistas en ninguno de los textos aprobados por el CNE.

Las conclusiones a que arribamos fueron:

7 Ver FONTANA, E. Los primeros textos escolares de historia argentina a nivel primario (1860-1890). Mendoza, Facultad de Filosofia y Letras (UNC) (mimeo), p. 8-10 y 46-47. El autor fue codirector de nuestro proyecto en 1994-1995 y responsable de los manuales de historia.

8 Ver Informe de la Educación Común de 1908-1909, presentado al Ministro de Instrucción Pública. Especialmente el capítulo 1: La educación nacionalista.

9 Ver GARCIA PELAYO, M. Las transformaciones del Estado Contemporáneo. Madrid: Alianza, 1987, p. 24-25.

10 Ver PUELLES BENTTEZ, M Estado y educación en las sociedades europeas. En: Revista Iberoamericana de Educación, n. 1.

11 Coincidimos con RAMOS DESAULNIERS, J. Memoria social e ciudadania, ponencia presentada al IV Congreso Iberoamericano de Historia de la Educación Latinoamericana. Santiago de Chile, Universidad Católica de Chile, mayo de 1998.

12 Ver: MUSCIA, A. Los manuales escolares de Moral e Instrucción Cívica en la escuela argentina (1884/1916). En: OSSENBACH, G. (c) Los manuales escolares como fuente para una Historia de la Educación en América Latina. Un análisis comparado. I Seminario Intemacional sobre Manuales Escolares, Proyecto MANES (Manuales Escolares de España y América Latina (1812-1990). Madrid: Universidad Nacional de Educación a Distancia, en prensa.

13 Los hallamos en la Biblioteca Nacional de Maestros; en la Biblioteca Nacional; la Biblioteca Pública "Gral. San Martín" de la Provincia de Mendoza y en bibliotecas escolares, tanto públicas como privadas de Mendoza.

14 Ibidem. Ver MUSCARA, F. "El positivismo en los libros de lectura". En: Revista Educación Cuyo, Mendoza, Facultad de Filosofia y Letras (UNC), n. 7. En prensa. 
1 - El paradigma común a todas las áreas era el del buen hombre y el buen ciudadano. 2 - Una concepción espiritualista del hombre fundamentaba la moral; 3 - La Moral tenía carácter preceptivo y no se derivaba de la ley positiva. 4 - los valores religiosos, confesionales, "sentimientos y creencias fundamentales", estaban a cargo de la familia.

La lucha por la educación se había librado en varios campos: legislatura, cátedras, grupos intelectuales, asociaciones civiles y religiosas, la gestión educativa y los periódicos, que contribuyeron a generar "grupos de opinión". Positivistas y católicos difundieron su ideal del ciudadano. La Iglesia contribuyó a crear conciencia de la necesidad de participar activamente en el campo político, social y educativo ante la "cuestión social" que asomaba. También como reacción ante la sanción de la Ley de Educación Común, una política que apostaba al progreso priorizando lo económico, el naturalismo fundamentando el aprendizaje y a todo un cambio de "símbolos" que alejaba cada vez más al ciudadano argentino de sus raíces.

Al no registrarse más concursos de textos de Moral a partir de 1901, buscamos otra vía: los planes de estudio y de los programas de la asignatura. ${ }^{15}$ Fue en los Programas de 1910 - que tuvieron vigencia hasta 1937 - donde encontramos lo que a primera vista pasó desapercibido. La Moral, indicaban, "debe darse ocasionalmente, aprovechando las otras enseñanzas [...]. En consecuencia, no puede ser una materia del programa ni tener un lugar fijo en el horario."16 En cambio la Instrucción Cívica tiene contenidos precisos desde primer grado. Si bien la Moral constituye el espiritu mismo de la escuela, ese espiritu coincide con una actitud empírica, concreta, práctica y también relativista, enmarcada en una moral cívica, que se nutre de "cuentos de índole moral, hechos históricos, ejemplos..." y cuya Ley Suprema es la Constitución Nacional.

Las clases no debian ser de carácter teórico. Las lecciones, regulares y fijas en el horario, deben preparar a los alumnos respecto a la organización política del país, de su gobierno y de las principales instituciones públicas. A ello concurren casi todas las asignaturas, como la historia "pues la historia patria brinda las mejores oportunidades para lecciones de civismo". En nota a pie de página, aparece el "dogma cívico": 1)"El primero y principal deber del hombre y del ciudadano es amar, honrar y servir a su Patria..." 2) "Buen ciudadano es el que conoce, respeta y ama a su Patria, y es fiel a las instituciones republicanas que la rigen..." Fórmula que los niños deberán aprender de memoria. ${ }^{17}$

15 Véase "Educación Moral e Instrucción Cívica a través de los Planes de Estudio y Programas (1884/1937)". En: NARADOWSKY, M.-LABAT, R. (C) Manuales escolares de Iberoamérica: avatares del pasado y nuevas tendencias. Segundo Seminario Iberoamericano de Historia de la Educación en América Latina. Proyecto MANES. Buenos Aires, Universidad Nacional de Quilmes, 1997 (en prensa).

16 "Plan de estudios para la escuela primaria. 1910". En: Digesto de Instrucción Primaria. Buenos Aires: CNE, 1920, p. 225.

17 Ibidem, p. 277. 
La "patria" fue el nuevo altar, los héroes sus "santos" y las fiestas respondian a una nueva "liturgia": la "semana de Mayo", la "semana de la Independencia", el día de la bandera, del árbol, del animal... las oraciones se dirigían "a la bandera". La imagen de la cruz fue reemplazada por la de una mujer: la "República" y el Dios cristiano por la Trinidad Democrática: Libertad, Igualdad e Fraternidad.18

Al desaparecer la Moral como asignatura preceptiva en los programas de este periodo (1910-1937) hallamos la huella del positivismo por el que nos preguntábamos.

18 Ver MUSCIA, A. Los manuales de Moral... y La educación Moral a través... 